\title{
Potential usefulness of enamel matrix derivative in skin and mucosal injury treatment
}

\author{
Sylwia Klewin-Steinböck ${ }^{1}$, Zygmunt Adamski², Marzena Wyganowska-Świątkowska ${ }^{1}$ \\ ${ }^{1}$ Department of Dental Surgery and Periodontology, Poznan University of Medical Sciences, Poznan, Poland \\ ${ }^{2}$ Department of Dermatology, Poznan University of Medical Sciences, Poznan, Poland
}

Adv Dermatol Allergol 2021; XXXVIII (3): 351-358

DOI: https://doi.org/10.5114/ada.2020.92318

\begin{abstract}
Enamel matrix proteins (EMP) are secreted by ameloblasts during odontogenesis. The main component of enamel protein extract is amelogenin. The extracts also contain proteins with bioactive properties similar to bone morphogenic proteins and transforming growth factor $\beta 1$. Research on animal models indicates that EMP improve healing of oral mucosa wounds by stimulating the production of collagen fibers and blood vessels in the connective tissue. Success in the treatment of oral wounds prompted interest in possible applications of amelogenins in the repair of damaged skin due to similarities in histological structure between skin and mucosa.
\end{abstract}

Key words: amelogenins, fibroblasts, skin, oral mucosa.

\section{Introduction}

Enamel matrix proteins (EMP) are secreted by ameloblasts during odontogenesis. Postnatally, EMP stimulate osteogenesis and cementogenesis during periodontal tissue regeneration processes. The main component of enamel protein extracts is amelogenin. The extract also contains proteins with bioactive properties similar to bone morphogenic proteins (BMPs) and transforming growth factor $\beta 1$ (TGF- $\beta 1$ ) [1]. Through their modulating effect on the activity of gingival and periodontal fibroblasts, proteins promote the regeneration and alteration of the gingival biotype. A recent study conducted on an animal model showed that the EMP improve the healing of oral mucosa wounds by stimulating the production of collagen fibers and blood vessels in the connective tissue. Success in the treatment of oral wounds prompted interest in possible applications of amelogenins in the repair of damaged skin due to similarities in histological structure between skin and mucosa. This is proven by recent genetic studies, carried out on ganoid scales of fish, demonstrating the primary occurrence of enamel in the skin in relation to the oral cavity ratio [2].

In vitro amelogenins stimulate the synthesis of the extracellular matrix molecules such as osteopontin, osteocalcin, hyaluronic acid, and type I collagen; stimulate cytokine expression (VEGF, PDGF-AB, IL-6, IGF-1); and regulate $C A M P$ and alkaline phosphatase. Interestingly, the amelogenins appear to affect connective and epithelial tissue cells differently [1].

Commercially used enamel matrix proteins (Emdogain), obtained from porcine fetal teeth, as enamel matrix derivative (EMD), are used in materials intended for the mouth and skin.

\section{Skin and oral mucosa - structure, role and differences}

Skin is the largest organ in the human body. It occupies an area of approximately $1.5-2 \mathrm{~m}^{2}$ and weighs between 18 and $20 \mathrm{~kg}$ with the subcutaneous tissue. It has both passive and active functions. Skin is a covering layer, a protective barrier against the penetration of biological (viruses, bacteria, fungi) and physical (UV radiation) agents. It has a thermoregulatory function due to its extensive vascular system, the presence of subcutaneous tissue and sweat glands. Additionally, it is involved in transepidermal water loss regulation.

Skin is a metabolically active structure. It synthesizes 7-dehydrocholesterol (an inactive form of vitamin $\mathrm{D}_{3}$ ) under the influence of UV radiation. Skin-associated lymphoid tissue (SALT) is an organ involved in the im-

Address for correspondence: Marzena Wyganowska-Świątkowska, Department of Dental Surgery and Periodontology, Poznan University of Medical Sciences, 70 Bukowska St, 60-812 Poznan, Poland, e-mail: marzena.wyganowska@periona.pl Received: 25.09.2019, accepted: 26.10.2019. 
munological processes. Keratinocytes produce biologically active cytokines - interleukin 1 (IL-1), interleukin 8 (IL-8), tumor necrosis factor $\alpha$ (TNF- $\alpha)$, transforming growth factor $\beta$ (TGF- $\beta$ ) and proopiomelanocorticotropin hormone. Langerhans cells can also produce cytokine. Additionally, skin-absorbing properties allow the absorption of various substances [3].

Skin consists of three layers - the epidermis, dermis and subcutaneous tissue. Epidermis is the most external layer and consists of four cell types. Keratinocytes are the most abundant cells in the epidermis, with the others being melanocytes, Langerhans cells and Merkel cells. Epidermis consists of four layers: stratum corneum, stratum granulosum, stratum spinosum, and stratum basale. However, on the palms of the hands and the soles of the feet, there are five epidermis cell layers, with stratum lucidum located between the stratum corneum and stratum granulosum. Stratum corneum is the most superficial layer and consists of flattened, dead keratinocytes called corneocytes. This layer prevents water loss, the penetration of allergens and infectious agents. In this layer, trans-isomer urocanic acid, which is responsible for maintaining skin acidity, is formed as well as pyrrolidone carboxylic acid, essential for maintaining proper skin hydration. Stratum granulosum, which lies under the stratum corneum, is composed of 3-5 layers of flattened, spindle cells. Located below the stratum spinosum, this layer is built of non-tightly adhered polygonal cells. The deepest layer of the epidermis is the stratum basale, made of a tightly adjacent cell layer. It is the reproductive layer of the epidermis. This layer contains keratinocytes, melanocytes, Langerhans cells and
Merkel cells. The epidermis is separated from the dermis by a basal membrane.

The dermis is composed of connective tissue, collagen and reticulin fibers, embedded in the extracellular matrix. It contains numerous cellular elements such as fibroblasts, myofibroblasts, dendritic cells, mast cells and inflammatory cells as well as nerves, lymphatic and blood vessels. The dermis contains two layers, the papillary and reticular dermis. The papillary layer is superficial and composed of loose connective tissue. This layer forms finger-like structures in the epidermis called papillae. Under the papillary dermis lies the reticular dermis, composed of dense connective tissue. This layer is responsible for skin thickness.

Subcutaneous tissue (hypodermis) is composed of adipocytes, fibrous connective tissue and blood vessels. Fibroblasts are the most abundant cells in the connective tissue with significant morphological and functional heterogeneity (Figure 1). There are three groups of fibroblasts in the dermis. In the papillary layer, the cells are small (4-7 nm), arranged horizontally and remain in contact with collagen fibers. In the reticular layer, fibroblasts' sizes increase and they are arranged along the collagen fibers. The third group of dermis fibroblasts is associated with the hair follicle, which can be separated into two subgroups of cells. The deeper the cells are located in the skin, the bigger the cells are. In the subcutaneous tissue the cells reach approximately $16 \mathrm{~nm}$, and their protrusions can reach $180 \mathrm{~nm}$ to form a network. Fibroblasts produce all components of the extracellular matrix and interact in dynamic and mutual interactions with other skin cells - epithelial cells, endothelial cells, nerve cells, adipocytes, inflammatory and stem cells, through direct

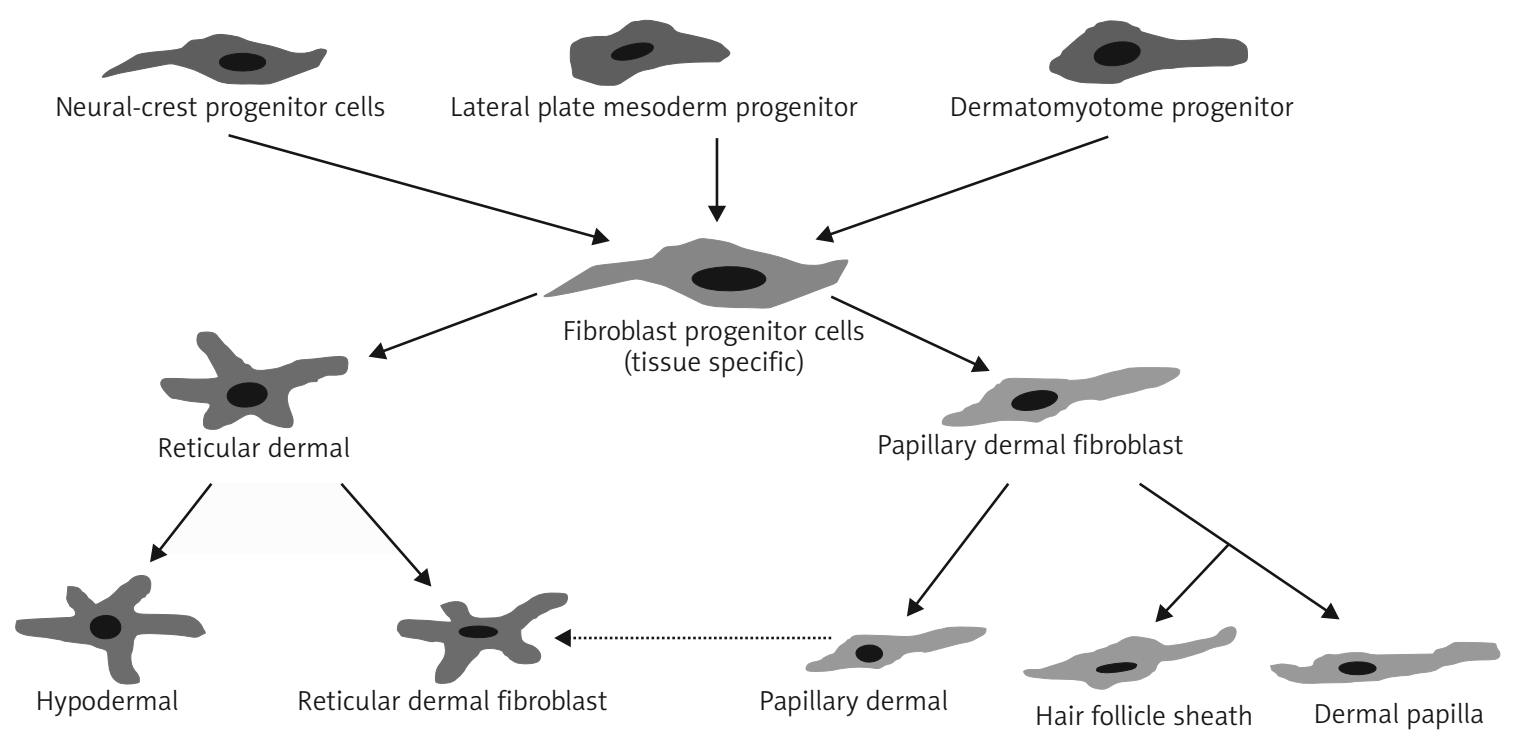

Figure 1. Fibroblast hetrogenity. Based on Srirama et al. [5] 
cell-cell communication, cell-matrix interaction, and by secretion of growth factors and cytokines [4, 5].

There is similarity between mucous membrane and skin. Mucosa protects deeper layers of tissues, and prevents microorganisms, antigens, and toxic substances from penetrating. Mucosa also completes secretory and absorption functions (e.g. drugs).

Gingival mucosa, part of the oral mucous membrane that covers the alveolar bone, is built of stratified squamous epithelium, oral epithelium, and an underlying connective tissue called lamina propria, which contains vascular components, that forms extensive capillary loops in the papillae between the epithelial ridges. The lack of submucosa tissue and the presence of keratinized epithelium are responsible for the pale color of healthy gingiva. Epithelium of keratinous gingiva has a structure similar to the epidermis and consists of four layers: stratum corneum, stratum granulosum, stratum spinosum, and stratum basale. Epithelial tissue consists mainly of keratinocytes, melanocytes (in a smaller number than in the epidermis), Langerhans cells and Merkel cells. The lamina propria is composed of fibrous connective tissue and can be distinguished into two layers, the papillary and the reticular. It contains bundles of collagen fibers and a small amount of elastic fibers. The most frequently represented cells are fibroblasts; other cells characteristic of connective tissue are also present - macrophages, mast cells, granulocytes, lymphocytes. Like in the dermis, fibroblasts exhibit morphological and functional differentiation [6, 7]. In contrast to the epidermis, the stratum corneum of the mucous membrane is thinner, and the epithelium also renews itself faster: 5-8 days as opposed to 28 days in the skin.

\section{Amelogenins - structure}

Amelogenins are a family of hydrophobic proteins secreted by ameloblasts (EMP), and are the largest group of extracellular matrix proteins (ECM), accounting for over $90 \%$ of all enamel proteins (with ameloblastin and enamelin accounting for $5 \%$ and $2 \%$ respectively) [8, 9]. Amelogenins have unusual amino acid composition, containing over $50 \%$ hydrophobic amino acids [8]. Approximately $25-30 \%$ of all amino acids are proline, with relatively high levels of histidine, glutamine and leucine [9]. Amelogenins are practically insoluble at physiological $\mathrm{pH}$ and body temperature but dissolve in high or low $\mathrm{pH}$ and at a low temperature. They self-aggregate spontaneously in vivo and in vitro, forming supramolecular structures called nanospheres, the size of which depends on the temperature changes. Amelogenin nanospheres are arranged in a precisely defined shape and size, which affects the microstructure and the increase in the length of the hydroxyapatite crystals [10-13]. Amelogenin expression has been observed in bone and cartilage cells - chondrocytes, osteoblasts and osteoclasts - as well as in soft tissues unrelated to odontogenesis, like the brain and some hematopoietic cells [12]. The fact that amelogenins are expressed in soft tissues suggests their multifunctionality.

The amelogenin gene is located on the sex chromosomes and is one of the best-known human genes. It is a highly conservative gene for various species, which contributes to the lack of allergic reactions and high compatibility in clinical trials [14]. Amelogenin has a very high sequence identity among examined vertebrates (> 80\%). Amelogenin is rich in both the tyrosine aminoterminal and the hydrophilic carboxy-terminal that are almost identical between species [10, 11]. In most species, the amelogenin gene has seven exons, with exon 4 not found in some of the species. Recently, exons 8 and 9 have been identified in human tissues [15]. Various isoforms of amelogenin are the result of alternative splicing of protein fragments.

The intact amelogenin molecule is a $25 \mathrm{kDa}$ protein. Three major domains are distinguished in this primary protein: a hydrophobic $\mathrm{N}$-terminal tyrosine-rich domain called the tyrosine-rich amelogenin peptide (TRAP); a middle hydrophobic region rich in proline; and a hydrophilic C-terminal domain $[10,16]$. The parent protein is rapidly processed intracellularly by cutting the C-terminal telopeptide, creating a $23 \mathrm{kDa}$ protein, and after further degradation a protein of a mass of $20 \mathrm{kDa}$ is produced and secreted into the extracellular matrix. Subsequently, the protein is enzymatically cut in two ways. In the main path, $20 \mathrm{kDa}$ amelogenin is cleaved into $11 \mathrm{kDa}$ (soluble) peptides and an intermediate form of $7 \mathrm{kDa}$, which is then degraded to $5 \mathrm{kDa}$ TRAP. The minor path leads to the formation of the tyrosine-rich amelogenin peptide (TRAP) with a mass of $5 \mathrm{kDa}$ and soluble $13 \mathrm{kDa}$ peptides. A leucine-rich peptide (LRAP) is formed as a result of the degradation of amelogenin formed from alternative splicing [9] (Figure 2).

\section{Amelogenins - role in tooth development}

Amelogenins' role in tooth development and posteruption repair processes is widely documented in in vitro and in vivo studies [17-19], particularly in connection with cement inhibition and dentin resorption. It inhibits odontoclast development, probably by regulating the expression of NF- $\kappa \mathrm{B}$ ligand-receptor activator (RANKL). In vitro studies indicated that the EMD effect on different cell biology is the result of both the activity of $20 \mathrm{kDa}$ amelogenin itself, and various protein fractions or growth factors [20]. Long-chain amelogenin fractions may stimulate autocrine production of BMP, while leucine-rich or tyrosine-rich fractions accelerate autocrine production of TGF- $\beta$. It is suggested that amelogenins may stimulate fibroblasts' secretion of TGF- $\beta$, which manifests itself in the ability to differentiate into various directions. Furthermore, bone morphogenetic proteins, primarily 


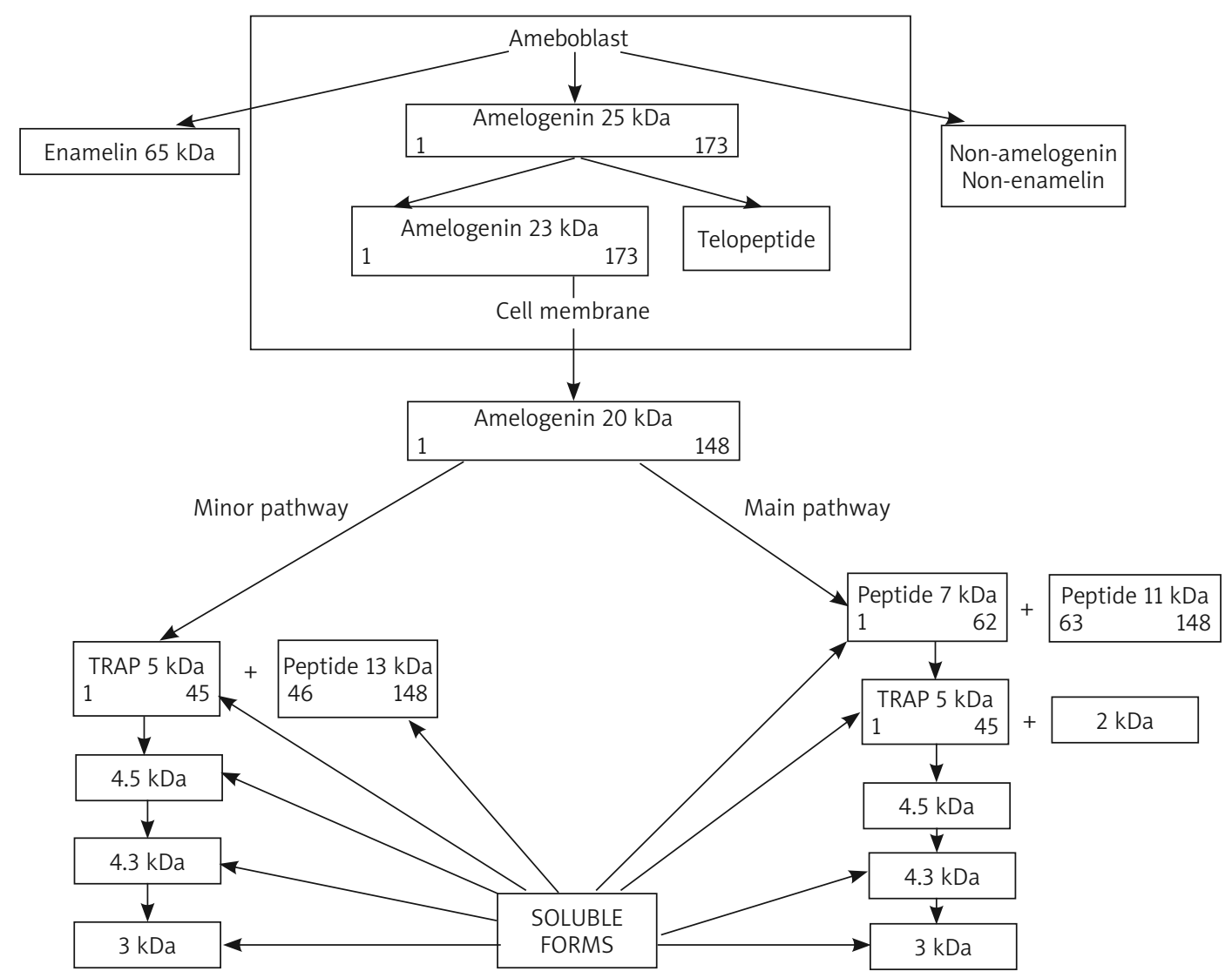

Figure 2. The process of extracellular proteolysis of amelogenins. Ameloblasts synthesize three categories of enamel matrix derived proteins: amelogenin, enamelin and nonamelogenin non-enamelin proteins. Amelogenin is slowly degraded by proteolytic extracellular enzymes to smaller, soluble forms [1]

responsible for osteogenesis and osteoinduction during bone repair, may have similar effects on periodontal tissues, including epithelial cells and fibroblasts, likely due to their role as regulators in epithelial-mesenchymal interaction processes [21].

The fibroblast phenotype is genetically modulated but is also strongly locally affected. Research on fibroblast morphology showed variations in response to stimuli between the fibroblasts present in periodontal tissues. Differences occurred in gingiva even within attached gingival fibroblasts and gingival papilla fibroblasts. The effect of EMD on periodontal and gingival fibroblasts is various. Research on the role of gingival fibroblasts in the regeneration process launched the hypothesis that only the cells in the vicinity of the damaged periodontium are capable of creating a new attachment with all its components. Gingival fibroblasts are perceived as specific progenitor cells. Among them, cells were isolated with typical osteogenic phenotype, which expressed osteocalcin and osteopontin genes, as well as increasing secretion of alkaline phosphatase or enzymes involved in mineralization [22]. Although fibroblasts' morphology seems to be described in detail, it is well known that their cell membrane contains many receptors for bioactive molecules. However, there is still little knowledge about the fibroblasts' surface markers, which would allow different fibroblasts to be distinguished.

Research confirmed however that EMD significantly affects fibroblasts' biology. The observed increase in the proliferative potential, without significant changes in cell morphology, is very promising, especially in the treatment of gingival recessions, wound healing, skin revitalization, as well as in stem cell therapy [23] (Figure 3).

\section{Amelogenins influence on epithelial cells}

Many EMD studies conducted on periodontal tissues have shown that the EMD effects on epithelial and mesenchymal cells can vary [24-26]. The results of research on the effects of EMD on oral epithelial cells are ambigu- 
ous. EMD has been shown to decrease the proliferation of epithelial cells [27, 28], but in many clinical trials, the acceleration of epithelial healing after intraoperative EMD use was observed [29-32]. It is suggested that EMD may induce malignant lesions in the mucosa, which means that patients with pre-cancerous or malignant lesions on the mucosa should not be treated with EMD [30].

In the previous study, the effect of amelogenin and the peptides of amelogenin degradation was analyzed on human tongue cancer cell line SCC-25 (squamous cell carcinoma). The study used: AMEL-GST made of recombinant prAMEL protein with a mass of $21.3 \mathrm{kDa}$ and glutathione transferase (GST), TRAP with a mass of $5.3 \mathrm{kDa}$ and EMD. The listed formulations were used at concentrations of $12.5,25$ and $50 \mu \mathrm{g} / \mathrm{ml}$, forming ten groups of studied cells. The impact on the morphology, adhesion, proliferation, and migration of cells was evaluated. Referring to cell morphology, adherence and migration, no significant differences were observed, regardless of the type and concentration of the preparation used (Figure 4). No significant differences were observed in cell proliferation after 12 -hour incubation in either of the groups tested.

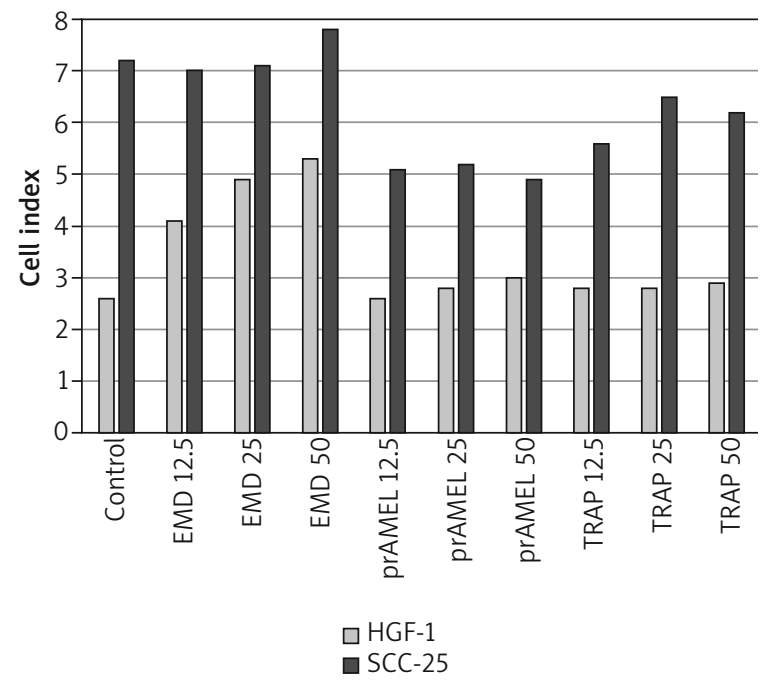

Figure 3. Effect of EMD, prAMEL and TRAP on the proliferation of human fibroblast (HGF-1) and cancer cell (SCC-25) after $48 \mathrm{~h}$ stimulation $[23,33]$
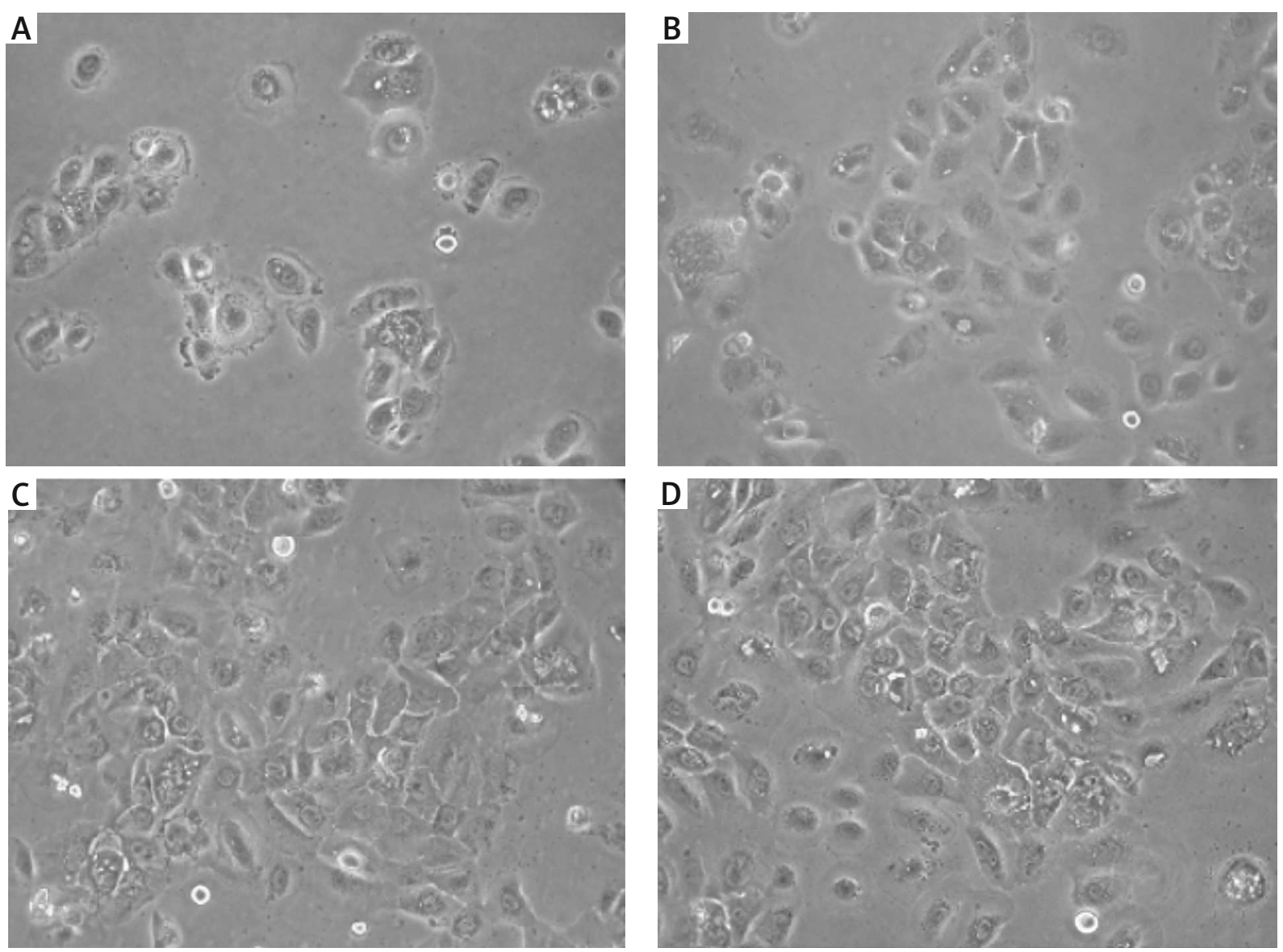

Figure 4. SCC-25 epithelial cell morphology after EMD stimulation. A - SCC-25 control cells after $24 \mathrm{~h}$. B - Cells after $48 \mathrm{~h}$ EMD stimulation. C - Control cells after 72 h. D - Cells after 72 h EMD stimulation. No significant changes in cell morphology were observed after EMD stimulation [33] 


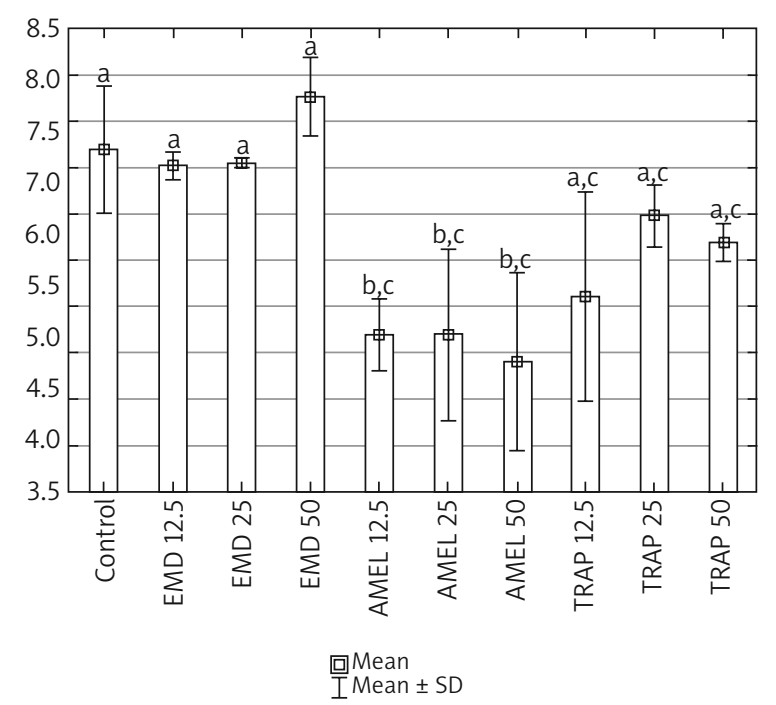

Figure 5. Effect of EMD, prAMEL and TRAP on the cancer cell proliferation intensity (SCC25) after $48 \mathrm{~h}$ stimulation [33]

However, after $24 \mathrm{~h}$ of incubation, a significant decrease in $\mathrm{Cl}$ (cell index) in the group stimulated with prAMEL $(12.5 \mathrm{\mu g} / \mathrm{ml})$ was noted as compared to cells stimulated with EMD (12.5 and $25 \mu \mathrm{g} / \mathrm{ml})$. Furthermore, after $48 \mathrm{~h}$ incubation, all the groups of cells treated prAMEL (12.5, 25 and $50 \mu \mathrm{g} / \mathrm{ml}$ ) showed a significant decrease in proliferation rate compared to the control group stimulated with EMD [33] (Figure 5). These results are compatible with the observations made in another study, which in dicated that the recombinant AMEL inhibits the growth rate, adhesion and migration of gingival epithelial cells [34]. Li et al. found that recombinant $\operatorname{AMEL}(25,25$, and $25 \mathrm{\mu g} / \mathrm{ml}$ ) inhibits human epithelial cell attachment, migration and growth of the gingival epithelium in a time and dose-dependent manner [34].

The results of other studies were inconclusive [35, 36] due to the use of different cell types (epithelial cells, tongue cancer, gingival fibroblasts, periodontal fiber cells) obtained from various species (rats, pigs, humans) and the use of various EMD components.

\section{Amelogenins' influence on connective tissue cells}

Gingival fibroblasts (GFs) are considered as a potential source of pluripotent stem cells used in regenerative processes not only in the mouth but also in the tissues located outside the oral cavity [37]. They affect the migration of keratinocytes and play an important role in mucous membrane wound healing - a process which includes cell migration, cell attachment to extracellular matrix components and cell proliferation [38]. Although GFs are phenotypically and functionally different from skin fibroblasts [39] and periodontal fibroblasts [40] an EMD response was observed in all of the cell types.
Amelogenins, the main component of EMD, products of amelogenin degradation (TRAP) or products resulting from alternative splicing (LRAP) have different biochemical properties [41, 42]. It has been shown that EMD significantly increases the proliferation of GF $[24,43]$ and that the process is time- and concentration-dependent. Amelogenins affect the adhesion of gingival fibroblasts rather than proliferation. Biological inactivity of TRAP [44] suggests the same as inhibitory effects of recombinant amelogenins on GF migration [34].

The next study [23] was performed on human gingival fibroblasts (HGF ATCC CRL-2014 line). AMEL-GST was used, consisting of prAMEL protein, with a mass of $21.3 \mathrm{kDa}$ and glutathione transferase (GST), TRAP with a mass of $5.3 \mathrm{kDa}$ and EMD. The formulation was used in the following concentrations: $12.5,25$ and $50 \mathrm{\mu g} / \mathrm{ml}$. The impact on the morphology, adhesion, proliferation and migration of cells was evaluated. No significant differences were observed in cell proliferation after $12 \mathrm{~h}$ incubation. However, after 24 and 48 h of incubation, a significant increase in $\mathrm{Cl}$ was found in the EMD stimulated cell group, for all of the concentrations used compared to the control group, prAMEL and prTRAP. In addition, all doses of PrAMEL and recombinant prTRAP administered for $48 \mathrm{~h}$ caused an increase in proliferation rate compared to control cells, with the difference significant only for prAMEL $50 \mu \mathrm{g} / \mathrm{ml}$. Analysis carried out after 60 and $72 \mathrm{~h}$ of incubation showed a significant increase in migration in the group stimulated by PrAMEL for all concentrations and in the group stimulated by prTRAP $12.5 \mathrm{pg} / \mathrm{ml}$, compared to both control and EMD groups. After $48 \mathrm{~h}$ stimulation with EMD or prAMEL, a significant decrease in the percentage of cells in the G0/G1 phase and an increase in the percentage of cells in the $S$ and G2/M phases was observed. No significant changes were observed in the cell cycle after prTRAP stimulation [23].

There are only a few publications related to the treatment of periodontal tissue using the TRAP peptide. Stout et al. [45] did not observe TRAP biological activity, and Amin et al. [46] found its negative effects on periodontium and alveolar bone.

\section{Amelogenins' impact on wound healing}

Wound healing is a multi-step, complex process involving migration, proliferation, and adhesion of cells to extracellular matrix components. In this process, various types of cells (fibroblasts, macrophages, lymphocytes) are involved, regulated by cytokines, growth factors, extracellular matrix components (fibrin, collagen, etc.) and tissue inhibitors $[47,48]$. Success in the clinical application of EMD in periodontal wound healing caused interest in the potential role of amelogenin in the repair of damaged skin. An in vivo study conducted by Mirastschijski et al. on rabbits showed that surface application of EMD on the wound promotes the formation of granulation tissue. Macroscopically the wound area was smaller (the assess- 
ment was carried out on days 3, 7 and 14), and the new granulation tissue was more resistant to injury, less prone to bleeding compared to the control group. Histopathological examination after 28 days showed that the more advanced stage of healing occurred in the EMD group; the structure of scar tissue was more mature, reflecting the disappearance of the blood vessels within the scar [49].

A similar study on pigs confirmed the results obtained previously. The evaluation performed after 5, 20 and 35 days showed a reduction in the width of wounds in the group treated with EMD as compared to the control group. On day 35, the wounds in the EMD group were almost completely healed. Histologically, the test group was characterized by a larger amount of connective tissue and better-shaped collagen [50].

Animal studies led to the development of amelogenin compounds for the treatment of skin wounds based on the original EMD product. Several clinical trials demonstrated the positive effect of EMD on difficult-to-heal ulcers such as venous leg ulcers, diabetic foot ulcers and pressure ulcers. Amelogenin proteins, which are biocompatible with ECM proteins applied to the wound bed, form a temporary matrix that acts as a supporting structure, to which skin fibroblasts can attach during the healing process. It has been shown that amelogenins significantly reduce the size of the ulcer, reduce the level of exudate and reduce the pain associated with the wound. It is worth noting that wounds persisting longer than 6 months and covering an area larger than $10 \mathrm{~cm}^{2}$ present the best response to amelogenin treatment [47, 51-54]. Research conducted so far suggests that amelogenins operate at least on two levels during the healing process. Products of amelogenin degradation directly affect cells, inducing a cascade of growth factors [11].

In vitro studies on human dermal fibroblasts showed that amelogenins increase cell proliferation and secretion of growth factors such as TGF- $\beta$, vascular endothelial growth factor (VEGF) and matrix metalloproteinase-2 (MMP-2) [50]. Other studies confirmed the EMD stimulating effect on the proliferation of human dermal fibroblasts [55].

\section{Summary}

The use of enamel matrix derivative in the treatment and support of the healing process of damaged skin is a recognized and applied method, although still limited. The main components of the mixture, in extract or in a recombinant form, provide excellent results and are promising not only in the process of healing, repair or regeneration, but also in the revitalization of skin.

\section{Conflict of interest}

The authors declare no conflict of interest.

\section{References}

1. Wyganowska-Świątkowska M, Urbaniak P, Nohawica MM, et al. Enamel matrix proteins exhibit growth factor activity: a review of evidence at the cellular and molecular levels. Exp Ther Med 2015; 9: 2025-33.

2. Qu Q, Haitina T, Zhu M, et al. New genomic and fossil data illuminate the origin of enamel. Nature 2015; 526: 108-11.

3. Elias PM. The skin barrier as an innate immune element. Semin Immunopathol 2007; 29: 3-14.

4. Driskell RR, Watt FM. Understanding fibroblast heterogeneity in the skin. Trends Cell Biol 2015; 25: 92-9.

5. Srirama G, Bigliardi PL, Bigliardi-Qi M. Fibroblast heterogeneity and its implications for engineering organotypic skin models in vitro. Eur J Cell Biol 2015; 94: 483-512.

6. Kmieć Z. Histologia I cytofizjologia zęba i jamy ustnej. Urban \& Partner, Wrocław 2006.

7. Knychalska-Karwan Z. Fizjologia i patologia błony śluzowej jamy ustnej. Czelej, Lublin 2009.

8. Honda MJ, Suda N. A new function of amelogenin - from bench to clinics, and clinics to bench. J Oral Biosci 2011; 53: 241-7.

9. Brookes SJ, Robinson C, Kirkham J, et al. Biochemistry and molecular biology of amelogenin proteins of developing dental enamel. Arch Oral Biol 1995; 40: 1-14.

10. Ruan Q, Moradian-Oldak J. Amelogenin and enamel biomimetics. J Mater Chem B 2015; 3: 3112-29.

11. Lyngstadaas SP, Wohlfahrt JC, Brookes SJ, et al. Enamel matrix proteins: old molecules for new applications. Orthod Craniofac Res 2009; 12: 243-53.

12. Deutsch D, Haze-Filderman A, Blumenfeld A, et al. Amelogenin, a major structural protein in mineralizing enamel, is also expressed in soft tissues: brain and cells of the hematopoietic system. Eur J Oral Sci 2006; 114: 183-9.

13. Bosshardt DD. Biological mediators and periodontal regeneration: a review of enamel matrix proteins at the cellular and molecular levels. J Clin Periodontol 2008; 35: 87-105.

14. Miron RJ, Sculean A, Cochran DL, et al. Twenty years of enamel matrix derivative: the past, the present and the future. J Clin Periodontol 2016; 43: 668-83.

15. Haruyama N, Hatakeyama J, Moriyama K, et al. Amelogenins: multi-functional enamel matrix proteins and their binding partners. J Oral Biosci 2011; 53: 257-66.

16. Salido EC, Yen PH, Koprivnikar K, et al. The human enamel protein gene amelogenin is expressed from both the $X$ and the Y chromosomes. Am J Hum Genet 1992; 50: 303-16.

17. Moradian-Oldak J, Simmer JP, Sarte PE, et al. Specific cleavage of a recombinant murine amelogenin at the carboxy- terminal region by a proteinase fraction isolated from developing bovine tooth enamel. Arch Oral Biol 1994; 39: 647-56.

18. Fincham AG, Hu Y, Lau EC, et al. Amelogenin post-secretory processing during biomineralization in the postnatal mouse molar tooth. Arch Oral Biol 1991; 36: 305-17.

19. Sire JY, Huysseune A. Formation of skeletal and dental tissues in fish: a comparative and evolutionary approach. Biol Rev 2003; 78: 219-49.

20. Yagi Y, Suda N, Yamakoshi Y, et al. In vivo application of amelogenin suppresses root resorption. J Dent Res 2009; 88: 176-81.

21. Häkkinen L, Larjava H, Fournier BPJ. Distinct phenotype and therapeutic potential of gingival fibroblasts. Cytotherapy 2014; 16: 1171-86.

22. Phipps RP, Borrello MA, Blieden TM. Fibroblast heterogeneity in the periodontium and other tissues. J Periodont Res 1997; 32: 159-65. 
23. Wyganowska-Swiatkowska M, Urbaniak P, Lipinski D, et al. Human gingival fibroblast response to enamel matrix derivative, porcine recombinant 21.3-kDa amelogenin and 5.3-kDa tyrosine-rich amelogenin peptide. Hum Cell 2017; 30: 181-91.

24. Kawase T, Okuda K, Yoshie H, et al. Anti-TGF-beta antibody blocks enamel matrix derivative-induced upregulation of p21WAF1/cip1 and prevents its inhibition of human oral epithelial cell proliferation. J Periodontal Res 2002; 37: 255-62.

25. Lyngstadaas SP, Lundberg E, Ekdahl H, et al. Autocrine growth factors in human periodontal ligament cells cultured on enamel matrix derivative. J Clin Periodontol 2001; 28: $181-8$

26. Grandin HM, Gemperli AC, Dard M. Enamel matrix derivative: a review of cellular effects in vitro and a model of molecular arrangement and functioning. Tissue Eng Part B Rev 2012; 18: 181-202.

27. Kawase T, Okuda K, Momose M, et al. Enamel matrix derivative (EMDOGAIN) rapidly stimulates phosphorylation of the MAP kinase family and nuclear accumulation of smad2 in both oral epithelial and fibroblastic human cells. J Periodontal Res 2001; 36: 367-76.

28. Kawase T, Okuda K, Yoshie H, et al. Cytostatic action of enamel matrix derivative (EMDOGAIN) on human oral squamous cell carcinoma-derived SCC25 epithelial cells. J Periodontal Res 2000; 35: 291-300.

29. Sanz M, Tonetti MS, Zabalegui I, et al. Treatment of intrabony defects with enamel matrix proteins or barrier membranes: results from a multicenter practice-based clinical trial. J Periodontol 2004; 75: 726-33.

30. Laaksonen M, Sorsa T, Salo T. Emdogain in carcinogenesis: a systematic review of in vitro studies. J Oral Sci 2010; 52: $1-11$.

31. Villa O, Wohlfahrt JC, Mdla I, et al. Proline-rich peptide mimics effects of enamel matrix derivative on rat oral mucosa incisional wound healing. J Periodontol 2015; 86: 1386-95.

32. Maymon-Gil T, Weinberg E, Nemcovsky C, at el. Enamel matrix derivative promotes healing of a surgical wound in the rat oral mucosa. J Periodontol 2016; 87: 601-9.

33. Wyganowska-Światkowska M, Urbaniak P, Lipinski D, et al. Effect of enamel matrix proteins on adherence, proliferatiom and migration of epithelial cells: a real-time in vitro study. Exp Ther Med 2016; 13: 160-8.

34. Li X, Shu R, Liu D, et al. Different effects of 25-kDa amelo genin on the proliferation, attachment and migration of various periodontal cells. Biochem Biophys Res Commun 2010; 394: 581-6.

35. Amin HD, Olsen I, Knowles JC, et al. Differential effect of amelogenin peptides on osteogenic differentiation in vitro: identification of possible new drugs for bone repair and regeneration. Tissue Eng Part A 2012; 18: 1193-202.

36. Frasheri I, Ern C, Diegritz C, et al. Full-length amelogenin influences the differentiation of human dental pulp stem cells. Stem Cell Res Ther 2016; 7: 10.

37. Egusa H, Okita K, Kayashima H, et al. Gingival fibroblasts as a promising source of induced pluripotent stem cells. PLoS One 2010; 5: e12743.

38. Rodrigues TL, Marchesan JT, Coletta RD, et al. Effects of enamel matrix derivative and transforming growth factorbeta1 on human periodontal ligament fibroblasts. J Clin Periodontol 2007; 34: 514-22.

39. Stephens P, Davies KJ, Occleston N, et al. Skin and oral fibroblasts exhibit phenotypic differences in extracellular matrix reorganization and matrix metalloproteinase activity. $\mathrm{Br}$ J Dermatol 2001; 144: 229-37.
40. Lekic PC, Pender N, McCulloch CAG. Is fibroblast heterogeneity relevant to the health, diseases, and treatments of periodontal tissues? Crit Rev Oral Biol Med 1997; 8: 253-68.

41. Sun Z, Fan D, Fan Y, et al. Enamel proteases reduce amelogenin-apatite binding. J Dent Res 2008; 87: 1133-7.

42. Tan J, Leung W, Moradian-Oldak J, et al. Quantitative analysis of amelogenin solubility. J Dent Res 1998; 77: 1388-96.

43. Rincon JC, Haase HR, Bartold PM. Effect of Emdogain on human periodontal fibroblasts in an in vitro wound-healing model. J Periodontal Res 2003; 38: 290-5.

44. Mumulidu A, Hildebrand B, Fabi B, et al. Purification and analysis of a $5 \mathrm{kDa}$ component of enamel matrix derivative. J Chromatogr B Anal Technol Biomed Life Sci 2007; 857: 210-8.

45. Stout BM, Alent BJ, Pedalino P, et al. Enamel matrix derivative: protein components and osteoinductive properties. J Periodontol 2014; 85: 9-17.

46.Amin HD, Olsen I, Knowles JC, et al. Differential effect of amelogenin peptides on osteogenic differentiation in vitro: identification of possible new drugs for $b o b=$ ne repair and regeneration. Tissue Eng Part A 2012; 18: 1193-202.

47. Romanelli M, Dini V, Vowden P, et al. Amelogenin, an extracellular matrix protein, in the treatment of venous leg ulcers and other hard-to-heal wounds: experimental and clinical evidence. Clin Intervent Aging 2008; 3: 263-72.

48. Kasuya A, Tokura Y. Attempts to accelerate wound healing. J Dermatol Sci 2014; 76: 169-72.

49. Mirastschijski U, Konrad D, Lundberg E, et al. Effects of a topical enamel matrix derivative on skin wound healing. Wound Repair Regen 2004; 12: 100-8.

50.Al-Hezaimi K, Al-Askar M, Al-Fahad H, at al. Effect of enamel matrix derivative protein on the healing of standardized epithelial wounds: a histomorphometric analysis in vivo. In Wound J 2012; 9: 436-41.

51. Schlueter SR, Carnes DL, Cochran DL. In vitro effects of enamel matrix derivative on microvascular cells. J Periodontol 2007; 78: 141-51.

52. Romanelli M. Amelogenin: extracellular matrix protein for the treatment of hard-to-heal wounds. Wounds UK 2010; 6: 47-52.

53. Vowden P, Romanelli M, Peter R, et al. The effect of amelogenins (Xelma ${ }^{T M}$ ) on hard-to-heal venous leg ulcers. Wound Rep Reg 2006; 14: 240-6.

54. Miron RJ, Dard M, Weinreb M. Enamel matrix derivative, inflammation and soft tissue wound healing. J Periodontal Res 2015; 50: 555-69.

55. Weinberg E, Topaz M, Dard M, et al. Differential effects of prostaglandin E2 and enamel matrix derivative on the proliferation of human gingival and dermal fibroblasts and gingival keratinocytes. J Periodont Res 2010; 45: 731-40. 